\title{
COLON
}

\section{Octreotide induced prolongation of colonic transit increases faecal anaerobic bacteria, bile acid metabolising enzymes, and serum deoxycholic acid in patients with acromegaly}

\author{
L A Thomas, M J Veysey, G M Murphy, D Russell-Jones, G L French, J A H Wass, R H Dowling
}

Gut 2005;54:630-635. doi: 10.1136/gut.2003.028431

See end of article for authors' affiliations

Correspondence to Dr M Veysey, Central Coast Health Teaching and Research Unit, University of Newcastle, Gosford Hospital, PO Box 361 Gosford, NSW 2250, Australia: mveysey@ doh.health.nsw.gov.au

Revised version received 9 July 2004

Accepted for publication 14 July 2004
Background: Acromegalic patients have slow colonic transit, increased rates of deoxycholic acid formation, and an increased prevalence of cholesterol gall stones, especially during long term octreotide treatment. However, the effects of this prolonged large bowel transit time on the numbers of faecal anaerobes and the activities of the enzyme systems which biotransform conjugated cholic acid into unconjugated deoxycholic acid (cholylglycine hydrolase and $7 \alpha$-dehydroxylase) are unknown.

Methods: Therefore, in 10 non-acromegalic controls, 11 acromegalic patients not treated with octreotide, and 11 acromegalics on long term (8-48 months) octreotide (100-200 $\mu$ g three times daily subcutaneously), we measured large bowel transit time and, in freshly voided faeces, the activities of the two bile acid metabolising enzymes, and related the results to the proportion of deoxycholic acid in fasting serum. Moreover, in patients with acromegaly, we measured quantitative bacteriology in faeces. Results: Mean large bowel transit time in acromegalics not treated with octreotide (35 (SEM 6.5) hours) was $66 \%$ longer than that in non-acromegalic controls (21 (3.1) hours; NS) and became further prolonged during octreotide treatment (48 (6.6) hours; $p<0.001)$. These octreotide induced changes in transit were associated, in acromegalic patients, with more total $\left(15.0(2.5) \vee 6.3(1.3) \times 10^{9}\right.$ colony forming units $(\mathrm{cfu}) / \mathrm{g} ; \mathrm{p}<0.05)$ and Gram positive (6.3 (2.3) v $\left.3.2(1.0) \times 10^{9} \mathrm{cfu} / \mathrm{g} ; \mathrm{p}<0.05\right)$ faecal anaerobes. Mean faecal cholylglycine hydrolase activity in the long term octreotide group $\left(22.0(6.0) \times 10^{-2} \mathrm{U} / \mathrm{mg}\right.$ protein) was $138 \%$ greater than that in non-acromegalic controls $\left(12.0(6.0) \times 10^{-2} ; p<0.01\right)$. Similarly, mean $7 \alpha$-dehydroxylase activity in octreotide treated acromegalics $\left(11.1(1.18) \times 10^{-4} \mathrm{U} / \mathrm{mg}\right.$ protein) was $78 \%$ greater than that in patients not receiving long term octreotide $\left(6.3(0.5) \times 10^{-4} ; p<0.001\right)$. The mean proportion of deoxycholic acid in fasting serum also increased from $18.0(2.88) \%$ in the untreated group to $29.6(2.3) \%$ during long term octreotide $(p<0.05)$. There were significant linear relationships between large bowel transit time and: (i) faecal $7 \alpha$-dehydroxylase activity; and (ii) the proportion of deoxycholic acid in fasting serum and between $7 \alpha$-dehydroxylase activity and the proportion of deoxycholic acid in serum.

Summary/interpretation: These data suggest that increased deoxycholic acid formation seen in acromegalics during octreotide treatment is due not only to the greater numbers of faecal anaerobes but also to increased activity of the rate limiting enzyme pathway ( $7 \alpha$-dehydroxylation) converting cholic acid to deoxycholic acid.
O ctreotide (OT) is a long acting analogue of somatostatin. It suppresses both growth hormone $(\mathrm{GH})$ and insulin-like growth factor $1(\mathrm{IGF}-1)^{1}$ and is therefore an effective treatment for acromegaly. However, after one to two years of OT therapy, 10-60\% (mean 29\%) of acromegalic patients develop cholesterol rich gall bladder stones (GBS). ${ }^{23}$

OT treatment impairs gall bladder emptying. ${ }^{4-6}$ However, this is not the sole mechanism for OT induced GBS formation: these iatrogenic stones may also develop as a result of prolonged intestinal transit. ${ }^{6-8}$ We showed previously that patients with OT induced GBS not only have prolonged large bowel transit but they also have changes in bile composition and physical chemistry similar to those seen in "conventional" gall stone disease (unrelated to acromegaly or OT treatment). ${ }^{9}$ Thus OT treated acromegalic patients have supersaturated bile, excess biliary cholesterol in vesicles, a high biliary vesicular cholesterol:phospholipid molar ratio, and abnormally rapid nucleation of cholesterol microcrystals. These changes are associated with a doubling in the mean per cent of deoxycholic acid (DCA) conjugates in gall bladder bile. Moreover the results of paired, before, and during OT treatment studies suggest that this increase in per cent DCA in bile is due to OT treatment, independent of iatrogenic stone formation. ${ }^{9}{ }^{10}$ Although we proposed that the mechanism for this increase in biliary DCA is prolongation of colonic transit, ${ }^{6} 7910$ we did not know how changes in large bowel transit time (LBTT) might increase the per cent DCA in serum and bile.

We previously studied spontaneous gall stone disease in nonacromegalic patients. ${ }^{11}$ In these studies, we found that gall stone carriers had increased numbers of both total anaerobes and Gram positive anaerobic bacteria capable of bile acid deconjugation (cholylglycine hydrolase) ${ }^{12}$ and $7 \alpha$-dehydroxylation ( $7 \alpha$-dehydroxylase). ${ }^{13}$ However, these data were measured in fresh caecal aspirates obtained during colonoscopy rather than in faeces. The gall stone carriers also had increased bile acid metabolising enzyme activities compared with stone free controls. It seemed important therefore to see whether

Abbreviations: cfu, colony forming units; $\mathrm{CGH}$, cholylglycine hydrolase; DCA, deoxycholic acid; GBS, gall bladder stones; GH, growth hormone; IGF-1, insulin-like growth factor 1; LBTT, large bowel transit time; OT, octreotide; $7 \alpha-\mathrm{DH}, 7 \alpha$-dehydroxylase; TLC, thin layer chromatography 
comparable changes in bacteriology and bile acid metabolising enzymes also occurred in acromegalic patients.

The aims of this study were to compare colonic transit, bile acid metabolising enzyme activities, and the per cent DCA (\%DCA) in fasting serum in control subjects and in two groups of acromegalic patients-those not treated with OT and those receiving long term OT treatment-and to compare quantitative faecal bacteriology in the two groups of patients with acromegaly. Then, using univariate analyses, we examined the interrelationships between: (i) LBTT; (ii) qualitative and quantitative changes in fresh faecal microflora; (iii) faecal bacterial deconjugating and $7 \alpha$-dehydroxylating enzyme activities; and (iv) \%DCA in fasting serum (and by implication in bile).

\section{STUDY DESIGN, PATIENTS, AND METHODS Study design}

With few exceptions, the design of this study was similar to that of our companion paper. ${ }^{11}$ Thus we again measured LBTT, quantitative bacteriology, the associated bile acid metabolising enzyme activities, and \%DCA in fasting serum. However, we did so in acromegalic patients not treated with OT and in those receiving long term OT therapy (none of whom had GBS) and compared the results with those in a historic group of non-acromegalic stone free controls (see below). Moreover, in the present study, we measured faecal, rather than proximal colonic, samples while in non-acromegalic control subjects there was no quantitative bacteriology. Furthermore, because the acromegalic patients lived in distant parts of the country and were unable to return to Guy's Hospital each day for retrieval of pH-telemetry data, we did not measure colonic luminal $\mathrm{pH}$.

\section{Patients}

Three groups of individuals were studied:

Non-acromegalic "controls" $(n=10)$

These patients were aged 48 (SEM 2.4) years (range 26-65) and six of them were women. All had undergone clinically indicated colonoscopy (because of fresh rectal bleeding in four, cancer surveillance in five, and symptoms of the irritable bowel syndrome in one) but were found, in retrospect, to have normal colons by endoscopy and on histology of mucosal biopsies.

The 10 patients in this group were common to 10 of the 20 "control subjects" in our companion paper. ${ }^{11}$ For this reason, the results for two of the six variables (LBTT and \%DCA in fasting serum) have been presented previously. ${ }^{11}$ However, we were able to obtain faecal samples from only 10 of these 20 historic controls: this was the sole basis for selecting this subset of individuals for comparison with acromegalic patients.

Acromegalic patients not treated with OT $(n=11)$ These individuals were aged 46 (3.5) years (range 30-68) and five were women.

\section{Acromegalic patients treated long term with OT} $(\mathrm{n}=11)$

These patients were aged 46 (2.9) years (range 31-70) and seven were women. They were treated for 8-48 months (median 22 months) with 100-200 $\mu$ g OT three times daily by subcutaneous injection.

In the 22 acromegalic patients, the diagnosis of acromegaly was based on the following criteria: failure of suppression of serum GH levels to less than $2 \mathrm{mU} / \mathrm{l}$ after an oral glucose $(75 \mathrm{~g})$ load; a mean daily serum GH level of more than $5 \mathrm{mU} / \mathrm{l}$ (averaged from five samples taken over a 12 hour period), and increased age adjusted IGF-1 levels in serum. ${ }^{14}$
All 32 individuals studied were gall stone free, as judged by ultrasound scanning of the biliary tree not more than one month before entering the study. All 32 were encouraged to maintain their normal diets and patterns of defecation during the investigations: none had taken antibiotics, laxatives, or other drugs known to affect intestinal transit or the colonic bacterial flora for one month before the study.

\section{Methods}

Large bowel transit time (LBTT)

Colonic transit was measured by the Metcalf technique. ${ }^{15}$ In brief, patients swallowed capsules containing radio-opaque markers on days 1, 2, and 3 of the study and then had a plain abdominal $x$ ray on day 4 to count the number of residual markers, and from this, LBTT was calculated using a simple formula. ${ }^{15}$

\section{Collection of fresh faecal samples}

Patients delivered a faecal sample to the Gastroenterology Unit within four hours of defecation. These samples were stored in sealed plastic containers and transferred to the Microbiology Department in an anaerobic transport bag within one hour of receipt. A $1 \mathrm{~g}$ aliquot of each faecal sample was homogenised with $10 \mathrm{ml}$ of sterile saline (rendered anaerobic with nitrogen gas). The homogenate was also maintained in an anaerobic environment during transfer to the collection point in the Microbiology Department.

\section{Quantitative bacteriology}

The microbiological techniques used in this study were based on those of Summanen and colleagues, ${ }^{16}$ as described previously. ${ }^{11}$ For all the patients studied, the time interval between measurement of LBTT and bile acid metabolising enzymes never exceeded 28 days.

\section{Bile acid metabolising enzyme activities}

A $10 \mathrm{ml}$ aliquot of each homogenised faecal sample was first sonicated in an ice bath.

Proteins in the sonicates were then precipitated using saturated ammonium sulphate, ${ }^{17}$ and their concentrations measured using the Lowry method. ${ }^{18}$ Bile acid metabolising enzyme activities were assayed, and the results expressed as units of enzyme activity per mg of faecal protein, where 1 unit $=1 \mu \mathrm{mol}$ of product formed per $\mathrm{mg}$ of bacterial protein per minute.

\section{(i) Deconjugation: cholylglycine hydrolase (CGH)}

The substrate for the deconjugation reaction was $10 \mathrm{mM}$ taurocholic acid, and $0.5 \mathrm{ml}$ of the protein extracts from the faecal homogenates were incubated with $0.5 \mathrm{ml}$ of this substrate, as previously described. ${ }^{19}$ The product of this reaction (unconjugated cholic acid) was extracted using a C18 column, ${ }^{20}$ isolated by thin layer chromatography (TLC), ${ }^{21}$ and measured with the $3 \alpha$-hydroxysteroid dehydrogenase enzyme assay ${ }^{22}$ at $340 \mathrm{~nm}$.

(ii) Dehydroxylation: the cholic acid $7 \alpha$-dehydroxylase $(7 \alpha-D H)$ system

The reaction conditions for this enzyme pathway were also as previously described. ${ }^{19}$ In brief, $0.5 \mathrm{ml}$ of the protein extract were incubated with $200 \mu \mathrm{l}$ of $2 \mathrm{mM}$ non-isotopic cholic acid (which was used to catalyse the reaction by substrate-enzyme induction ${ }^{23}$ ), plus $200000 \mathrm{dpms}$ of ${ }^{14} \mathrm{C}$-cholic acid. Bile acids in the reaction mixture were extracted twice using ethyl acetate, separated, and the product (unconjugated DCA) identified using TLC. The ${ }^{14} \mathrm{C}$ radioactivity in this DCA fraction was then measured in a liquid scintillation counter (LKB 81,000; Sweden), using both internal and external quench correction. ${ }^{24}$ 
Measurement of \%DCA in fasting serum

Concentrations of individual bile acids were measured in fasting serum using gas chromatography-mass spectrometry, ${ }^{25-27}$ as previously described. ${ }^{7}$ The relative proportions of total DCA in serum were then calculated and expressed as percentages of total serum bile acids, respectively.

\section{Statistical analyses}

Unless otherwise stated, results are expressed as means (SEM). The significance of differences in results between the groups was tested using the hetroscedastic $t$ test, using Excel software version 5.0 (Microsoft Corporation, Redmond, Washington, USA). A p value of $<0.05$ was considered to be statistically significant.

We used univariate analyses to examine the relationships between: (i) LBTT; (ii) qualitative and quantitative changes in the fresh faecal microflora; (iii) faecal bacterial deconjugating and $7 \alpha$-dehydroxylating enzyme activities; and (iv) $\%$ DCA in fasting serum.

\section{Ethical considerations}

The study was approved by the Research Ethics Committee of Guys and St Thomas' Hospitals. All 32 patients gave written informed consent.

\section{RESULTS}

\section{Large bowel transit time (LBTT)}

The results for LBTT in the three groups of individuals are shown in fig 1.

There was a considerable scatter of results with some overlap for data between the three groups and although the mean value in acromegalic patients not treated with OT (35 (6.5) hours) was $66 \%$ greater than that in non-acromegalic controls (21 (3.1) hours), this difference was not statistically significant. However, in OT treated acromegalics, the mean value of 48 (6.6) hours was $129 \%$ greater than that in controls $(p<0.001)$ and $37 \%$ greater than that in untreated acromegalics $(\mathrm{p}<0.05)$.

\section{Faecal total and Gram positive anaerobic bacterial counts}

The mean total anaerobic count in acromegalic patients treated long term with octreotide $\left(15.0 \quad(2.5) \times 10^{9}\right.$ colony forming units (cfu)/g faeces) was $138 \%$ greater than that in acromegalic patients not treated with OT $\left(6.3(1.3) \times 10^{9} \mathrm{cfu} / \mathrm{g}\right.$ faeces; $\mathrm{p}<0.05$ ).

There was a similar pattern of results for Gram positive anaerobes; the mean count in OT treated patients (6.3

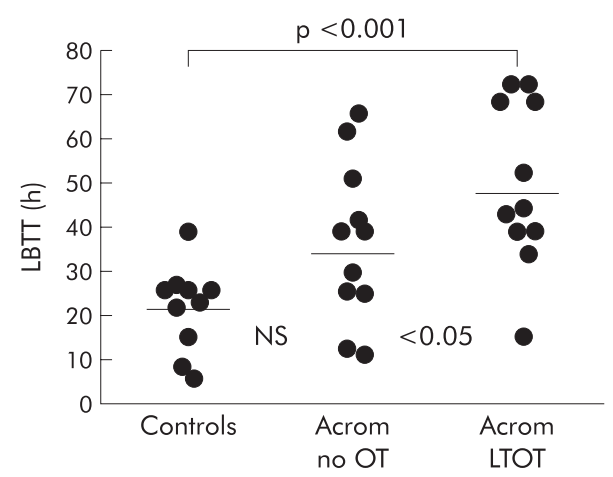

Figure 1 Large bowel transit time (LBTT: individual data points with means) in non-acromegalic control subjects, acromegalic patients not treated with octreotide (Acrom no OT), and acromegalic patients on long term octreotide treatment (Acrom LTOT).

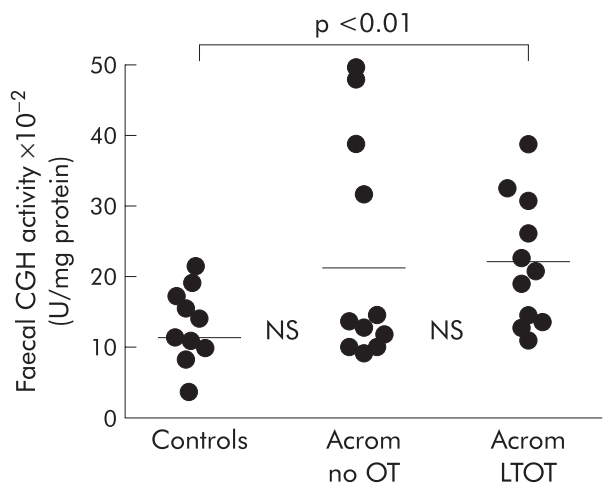

Figure 2 Faecal cholylglycine hydrolase (CGH: individual data points with means) specific activity in non-acromegalic control subjects, acromegalic patients not treated with octreotide (Acrom no OT), and acromegalic patients on long term octreotide treatment (Acrom LTOT).

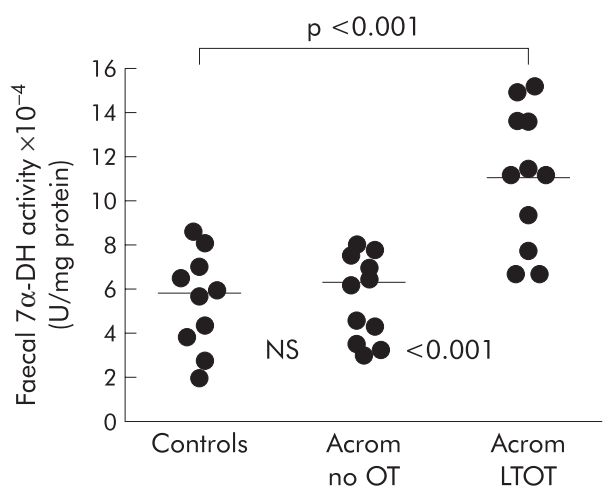

Figure 3 Faecal $7 \alpha$-dehydroxylase $(7 \alpha-\mathrm{DH})$ specific activity (individual data points with means) in non-acromegalic control subjects, acromegalic patients not treated with octreotide (Acrom no OT), and acromegalic patients on long term octreotide treatment (Acrom LTOT).

$(2.3) \times 10^{9} \mathrm{cfu} / \mathrm{g}$ faeces) was $97 \%$ greater than that in acromegalic patients who had not been treated with the somatostatin analogue $\left(3.2(1.0) \times 10^{9} \mathrm{cfu} / \mathrm{g}\right.$ faeces; $\left.\mathrm{p}<0.05\right)$.

\section{Bile acid metabolising enzyme activities}

Deconjugation: cholylglycine hydrolase

The results for CGH activity in all three groups of patients are shown in fig 2.

The overall pattern of results for CGH was broadly similar to that described above for LBTT. Despite a $75 \%$ increase in mean activity, there was no significant difference between controls $\left(12.0 \quad(6.0) \times 10^{-2}\right.$ units of enzyme activity/mg protein) and acromegalics not treated with OT (21.0 $(9.0) \times 10^{-2} \mathrm{U} / \mathrm{mg}$ protein), and no significant difference between the two groups of acromegalic patients. However, mean CGH in acromegalic patients on long term OT 22.0 $(6.0) \times 10^{-2} \mathrm{U} / \mathrm{mg}$ protein) was significantly greater than that in non-acromegalic controls $(\mathrm{p}<0.01)$.

\section{$7 \alpha$-dehydroxylation: cholic acid $7 \alpha$-dehydroxylase} $(7 \alpha-\mathrm{DH})$

Data for $7 \alpha-\mathrm{DH}$ specific activities are illustrated in fig 3 .

The pattern of results for the dehydroxylating enzyme system was also similar to those for LBTT and the deconjugating enzyme (CGH). Again, the highest specific activities were seen in acromegalic patients on long term octreotide treatment in whom the mean value of 11.13 $(1.18) \times 10^{-4} \mathrm{U} / \mathrm{mg}$ protein was $78 \%$ greater than that in 


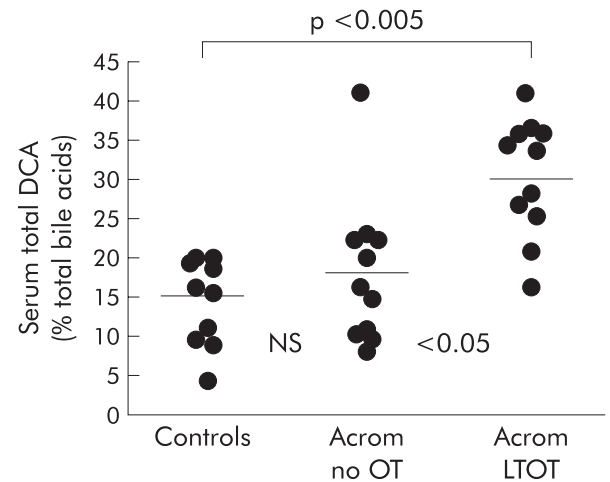

Figure 4 The proportion of deoxycholic acid (\%DCA: individual data points with means), expressed as a percentage of total serum bile acids, in non-acromegalic control subjects, acromegalic patients not treated with octreotide (Acrom no OT), and acromegalic patients on long term octreotide treatment (Acrom LTOT).

acromegalics not treated with octreotide $\left(6.25(0.52) \times 10^{-4}\right.$; $\mathrm{p}<0.001)$ and $88 \%$ greater than that in non-acromegalic controls $\left(5.93(0.40) \times 10^{-4} ; \mathrm{p}<0.001\right)$.

\section{Fasting serum deoxycholic acid}

The results for fasting serum total DCA, expressed as a percentage of serum total bile acids, are shown in fig 4 .

As with other variables, there was no significant difference in the mean proportions of DCA between non-acromegalic controls $(14.9(1.85) \%)$ and patients with acromegaly who had not been treated with the somatostatin analogue (18.0 $(2.88) \%)$. However, in acromegalic patients treated chronically with OT, the mean proportion of DCA (29.6 (2.3)\%) was significantly greater than that in acromegalics who had not been treated with OT $(p<0.05)$, and than that in controls $(\mathrm{p}<0.001)$.

\section{Relationship between LBTT and the faecal $7 \alpha-D H$ enzyme pathway}

The relationship between LBTT and the activity of the $7 \alpha-\mathrm{DH}$ enzyme system is plotted graphically in fig 5 .

As indicated in fig 5 , there was a weak $(r=0.57)$ but significant $(\mathrm{p}<0.001)$ positive linear relationship between

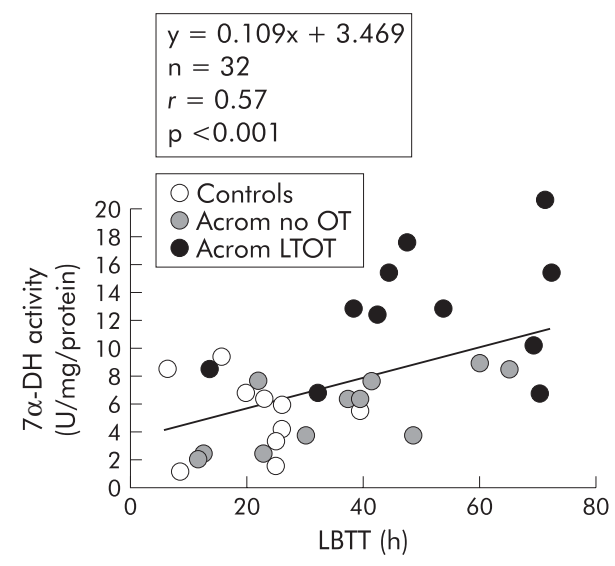

Figure 5 Relationship between large bowel transit time (LBTT) and $7 \alpha$-dehydroxylase ( $7 \alpha-\mathrm{DH})$ activity, expressed in enzyme units per $\mathrm{mg}$ of protein, in non-acromegalic control subjects, acromegalic patients not treated with octreotide (Acrom no OT), and acromegalic patients on long term octreotide treatment (Acrom LTOT).

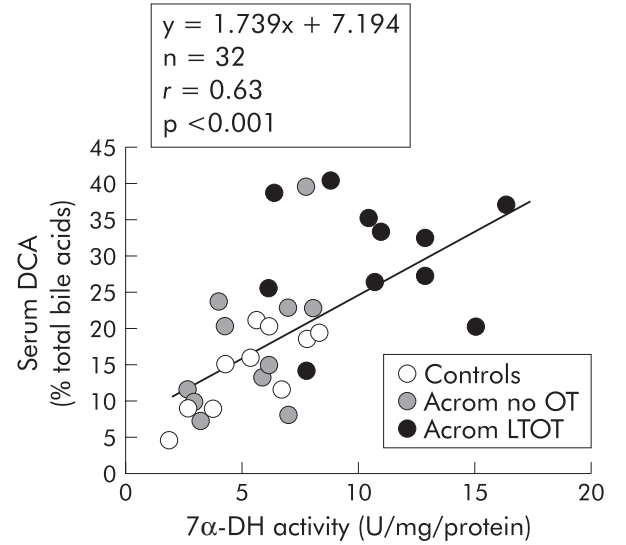

Figure 6 Relationship between $7 \alpha$-dehydroxylase $(7 \alpha-\mathrm{DH})$ activity, expressed as enzyme units per $\mathrm{mg}$ of protein, and the proportion of deoxycholic acid (DCA), expressed as a percentage of total serum bile acids, in non-acromegalic control subjects, acromegalic patients not treated with octreotide (Acrom no OT), and acromegalic patients on long term octreotide treatment (Acrom LTOT).

these two variables - that is, the longer the colonic transit time, the greater was the specific activity of the rate limiting enzyme pathway in DCA formation.

\section{Relationship between faecal $7 \alpha-D H$ activity and \%DCA in fasting serum}

The plot of serum DCA (\% of total bile acids) versus faecal $7 \alpha-\mathrm{DH}$ activity is shown in fig 6 .

The correlation coefficient for these two variables $(r=0.63)$ was slightly higher than that noted in fig 5, and again this linear relationship was statistically significant $(p<0.001)$.

Relationship between LBTT and \%DCA in fasting serum As prolongation of colonic transit is linearly related to $7 \alpha-\mathrm{DH}$ activity (fig 5), and as high faecal $7 \alpha-\mathrm{DH}$ activities are associated with increased proportions of DCA in fasting serum (fig 6), it follows that LBTT might be related to \%DCA in serum. This indeed proved to be the case: the correlation coefficient $(r)$ between \%DCA in serum and LBTT was 0.82 $(\mathrm{p}<0.001)$.

\section{DISCUSSION}

This study forms part of an ongoing programme of research in our unit into the pathogenesis of cholesterol rich

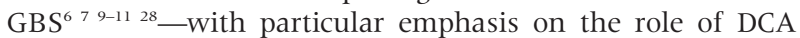
in the development of OT induced, and spontaneously occurring, GBS. The results of the present study, when combined with those of our companion paper, ${ }^{11}$ suggest that prolongation of colonic transit leads to increased numbers of total and Gram positive anaerobic bacteria, and increased activities of the bile acid deconjugating and $7 \alpha$-dehydroxylating enzymes, within the colon. In turn, this combination of events leads to increased proportions of DCA in serum and, by implication, in bile-a putative, ${ }^{29}$ although controversial, risk factor for cholesterol gall stone formation.

Why prolongation of large bowel transit should increase the numbers of anaerobic bacteria in the colon ${ }^{11}$ and faeces is not clear but there are several possible explanations. Firstly, the increased residence time of luminal contents within the colon could allow more time for bacterial proliferation. Secondly, transit related changes in colonic luminal $\mathrm{pH}$ may be important. Prolongation of LBTT is known to increase colonic luminal $\mathrm{pH}^{30-32}$ and in vitro (that is, in a "Chemostat" system), increases in $\mathrm{pH}$ encourage the growth of anaerobic bacteria, including Gram positive anaerobes.. ${ }^{33}$ Thirdly, 
although we have argued that it is the slowing of large bowel transit which is responsible for the greater numbers of colonic bacteria in acromegalic patients (particularly those treated long term with OT), in theory it could be DCA itself-rather than the prolonged transit-which influences bacterial growth.

\section{Study design, patients, and methods \\ Patient selection}

Although the main emphasis in this report was on acromegalic patients (studied before and during octreotide therapy), we felt it important to also include a control group of non-acromegalic stone free individuals. We did so because of the unresolved controversy about whether acromegaly itself (independent of OT treatment) is a risk factor for cholesterol stones. ${ }^{34-36}$ For this reason, we recruited the subset of 10 stone free individuals from a total of 20 controls in our companion study. ${ }^{11}$ In part, therefore, these 10 were historic controls and some of their results have been presented previously. However, they were selected solely on the basis of their ability and willingness to provide faecal samples. We believe that this selection criterion did not bias the results: certainly mean LBTTs and mean proportions of DCA in fasting serum in this subgroup of patients were not significantly different from those in the original 20 stone free controls. ${ }^{11}$

\section{Faecal $v$ caecal sampling for quantitative bacteriology and measurement of bile acid metabolising enzyme activities}

In our companion report, ${ }^{11}$ we studied quantitative bacteriology and bile acid metabolising enzyme activities in caecal aspirates, rather than in freshly voided faeces. Indeed, there were compelling theoretical reasons for doing so. The numbers of anaerobes are different at the two sites ${ }^{37}$ - bile acid deconjugation and $7 \alpha$-dehydroxylation take place mainly in the caecum and ascending colon, ${ }^{12}{ }^{13} 38$ rather than in the left side of the colon. That being the case, why did we opt to sample faeces in the present study? We did so for three reasons. Firstly, the present study was carried out mainly in acromegalic patients in whom colonoscopy is technically difficult, in part because they have long colons. ${ }^{39}$ Secondly, acromegalic patients have a high prevalence and incidence of large bowel polyps and cancers, ${ }^{40}{ }^{41}$ many of which are found on the right side of the colon. For this reason many centres, including our own, recommend that acromegalic patients should undergo endoscopy of the whole colon (and not just left sided flexible sigmoidoscopy) to exclude polyps and cancers. This involves full bowel preparation with oral purgation. Had we adopted such an approach in the present study, it would inevitably have disturbed the normal bacterial flora, and probably also the bile acid metabolising enzyme activities in the caecum. For ethical reasons, we did not feel justified in proposing two colonoscopic examinations in these patients: (i) a clinically indicated full colonoscopy (after oral purgation) to exclude polyps and cancers, and (ii) a limited examination of the left side of the colon (instant enema only with no oral purgation) plus caecal sampling for clinical research purposes.

Thirdly, in a separate, but related, study ${ }^{38}$ we compared bacterial bile acid metabolising enzyme activities in caecal and faecal samples, obtained at the same time from the same individuals. Although CGH activities were comparable at both sites, the mean activity of $7 \alpha-\mathrm{DH}$ in faeces was significantly lower than that in aspirates from the proximal colon. However, the magnitude of the difference in $7 \alpha-\mathrm{DH}$ activity between the caecal and faecal samples was small. Moreover, $7 \alpha-\mathrm{DH}$ activity at one site predicted that at the other.
Comparison of results in non-acromegalic controls and acromegalic patients not treated with octreotide As the present results show, for three of the four variables measured (LBTT, CGH activity, and \%DCA in serum), mean values in acromegalic patients not treated with OT were 23$75 \%$ higher than those in non-acromegalic controls. However, none of these differences was statistically significant: in part because of the scatter of results and in part because of the relatively small numbers in the two groups studied. The fact remains that in a previous study ${ }^{7}$ we found that mean LBTT and \%DCA in fasting serum were significantly greater in acromegalic patients who had not received OT than in nonacromegalic controls. Moreover, when the data from five separate studies (in which the same protocol was used) were pooled, ${ }^{42}$ untreated acromegalics showed obvious and significant increases in both parameters compared with nonacromegalic controls.

The implication of these observations is that one might expect an increased prevalence of cholesterol gall bladder stones in acromegaly. The evidence on this point is inconclusive because the number of studies addressing this problem is limited, ${ }^{34-36} 43-45$ the numbers of individuals surveyed in these studies were small, and comparisons in them were not based on case control studies but rather on values for gall stone prevalence from previously published epidemiological studies. In fact, Catnach and colleagues ${ }^{35}$ found a significant increase in the prevalence of gall stones in British acromegalic patients compared with that in age and sex matched controls from Bristol. ${ }^{46}$

The relevance of the present observations to spontaneous gall stone disease, and indeed to OT induced gall stones in acromegaly, depends on the validity of several assumptions: (i) that \%DCA in serum is a valid surrogate marker for the proportion of this hydrophobic bile acid in bile, (ii) \%DCA in bile influences biliary cholesterol secretion and saturation, and (iii) that supersaturated gall bladder bile itself predicts the risk of cholesterol gall stone formation. We believe that these assumptions are probably valid although the evidence to support them is reasonable rather than strong. This evidence has been reviewed fully elsewhere ${ }^{8}$ and need not be repeated here.

Even if there is an increased incidence and/or prevalence of gall stones in acromegalic patients not treated with somatostatin analogues, the fact remains that the pathogenesis of all cholesterol rich GBS is multifactorial. Therefore, even if present, the roles of prolonged colonic transit and of increased DCA formation/absorption in the genesis of gall stones in acromegaly may be modest.

\section{ACKNOWLEDGEMENTS}

We are grateful to Professor Phil Hylemon, Virginia Commonwealth University, Richmond, Virginia, USA, for his valued assistance in establishing our enzyme assay techniques, and to Dr Nigel Smeeton, GKT School of Medicine, for his help with statistics and study design.

\section{Authors' affiliations}

L A Thomas, M J Veysey, G M Murphy, R H Dowling, Gastroenterology Unit, Division of Medicine, Guys Hospital Campus, GKT School of Medicine, Kings College, London, UK

D Russell-Jones, Department of Endocrinology, St Thomas Campus, GKT School of Medicine, Kings College, London, UK

G L French, Department of Microbiology, St Thomas Campus, GKT School of Medicine, Kings College, London, UK

J A H Wass, Department of Endocrinology, Radcliffe Infirmary, Oxford, UK

Conflict of interest: None declared.

This work was presented in part at the Meeting of the American Gastroenterological Association (Gastroenterology 1998:114;A546). 


\section{REFERENCES}

1 Salmela PI, Juustila $\mathrm{H}$, Pyhtinen J. Effective clinical response to long term octreotide treatment with reduced serum concentrations of growth hormone, insulin-like growth factor-1, and the amino terminal propeptide of type III procollagen in acromegaly. J Clin Endocrinol Metab 1990;70:1193-201.

2 Dowling RH, Hussaini SH, Murphy GM, et al. Gallstones during octreotide therapy. Metabolism 1992:41(suppl 2):22-33.

3 Redfern JS, Fortuner WJ. Octreotide-associated biliary tract dysfunction and gallstone formation: pathophysiology and management. Am J Gastroenterol 1995;90:1042-52.

4 Lembcke B, Creutzfeldt W, Schlesser S, et al. Effect of somatostatin analogue Sandostatin (SMS 201-995) on gastro-intestinal, pancreatic, and biliary function, and hormone release in normal men. Digestion 1987;36:108-24.

5 van Leissum PA, Hopman WP, Pieters GF. Postprandial gallbladder motility during long term treatment with the long-acting somatostatin analogue SMS 201-995 in acromegaly. J Clin Endocrinol Metab 1989:69:557-62.

6 Hussaini SH, Pereira SP, Veysey MJ, et al. The roles of gallbladder emptying and intestinal transit in the pathogenesis of octreotide-induced gallbladder stones. Gut 1996;38:775-83.

7 Veysey MJ, Thomas LA, Mallet Al, et al. Prolonged large bowel transit increases serum deoxycholic acid-a risk factor for octreotide-induced gallbladder stones. Gut 1999;44:675-82.

8 Dowling RH. The role of intestinal transit. In: Afdhal NH, ed. Gallbladder and biliary tract diseases. New York: Marcel Dekker Inc, 2000:297-315.

9 Hussaini SH, Murphy GM, Kennedy C, et al. The role of bile composition and physical chemistry in the pathogenesis of octreotide-associated gallbladder stones. Gastroenterology 1994;107:1503-13.

10 Hussaini SH, Pereira SP, Murphy GM, et al. Deoxycholic acid influences cholesterol solubilisation and microcrystal nucleation time in gallbladder bile. Hepatology 1995;22:1735-44

11 Thomas LA, Bathgate T, Veysey MJ, et al. Mechanism for the transit-induced increase in colonic deoxycholic acid formation in cholesterol cholelithiasis. Gastroenterology 2000;119:806-15.

12 Nair PP, Gordon M, Reback J. The enzymatic cleavage of the carbon-nitrogen bond in $3 \alpha, 7 \alpha, 12 \alpha$-trihydroxy-5 $\alpha$-cholan-24-oyl glycine. J Biol Chem 1967;243:7-11

13 Stellwag EJ, Hylemon PB. $7 \alpha$ dehydroxylation of cholic acid and chenodeoxycholic acid by Clostridium leptum. J Lipid Res 1979;20:325-33.

14 Duncan E, Wass JAH. Acromegaly and its investigation. Clin Endocrinol 1999:334:285-93.

15 Metcalf AM, Phillips SF, Zinsmeister AR, et al. Simplified assessment of segmental colonic transit. Gastroenterology 1987;92:40-7.

16 Summanen P, Baron E, Citron D, et al. Wadsworth anaerobic bacteriology manual, 5th edn. Belmont, California: Star Publishing Company, 1993.

17 Murray RK, Granner DK, Mayer PA, et al. Harpers biochemistry, 2nd edn. Stamford, USA: Appleton and Lange, 1988:55-6.

18 Lowry OH, Rosebrough NJ, Farr AL, et al. Protein measurement with the Folin phenol reagent. J Biol Chem 1951;193:265-75.

19 Thomas LA, King A, French GL, et al. Cholylglycine hydrolase and $7 \alpha$ dehydroxylase optimum assay conditions in vitro and caecal enzyme activities ex vivo. Clin Chim Acta 1997;268:61-72.

20 Rodriques CMP, Setchell KDR. Performance characteristics of reverse-phase bonded silica cartridges for serum bile acid extraction. Biomed Chromatogr 1996;10:1-5.

21 Eneroth P. Thin layer chromatography of bile acids. J Lipid Res 1963;4:11-16

22 Bruusgard A. Quantitative determination of the major 3-hydroxy bile acids in biological material after thin-layer chromatographic separation. Clin Chim Acta 1970;28:495-504.

23 White BA, Lipsky RH, Fricke RJ, et al. Bile acid induction specificity of $7 \propto$ dehydroxylase activity in an intestinal Eubacterium sp. Steroids 1980;35:103-9.
24 Schrodt AG, Gibbs JA, Cavanagh RE. Quench correction by automatic external standardisation. Adv Tracer Meth 1965;2:155-62

25 Setchell KDR, Matsui A. Serum bile acid analysis. Clin Chim Acta 1983;127:1-17.

26 Goto J, Watanabe K, Miura H, et al. Trace analysis of bile acids by gas chromatography-mass spectrometry with negative ion chemical ionisation detection. J Chromatogr 1987; 388:379-87.

27 Stellaard F, Langelaar A, Kok RM, et al. Determination of plasma bile acids by capillary gas-liquid chromatography-electron capture negative chemical ionisation mass fragmentography. J Lipid Res 1989;30:1647-52.

28 Hussaini SH, Pereira SP, Murphy GM, et al. The composition of octreotideassociated gallbladder stones: response to oral ursodeoxycholic acid. Gut 1995:36:126-32.

29 Marcus SN, Heaton KW. Deoxycholic acid and the pathogenesis of gallstones. Gut 1988;29:522-33.

30 El Oufir L, Flourie B, Bruley des Varannes S, et al. Relations between transit time, fermentation products, and hydrogen consuming flora in healthy humans. Gut 1996;38:870-7.

31 Lewis SJ, Heaton KW. Increasing butyrate concentration in the distal colon by accelerating intestinal transit. Gut 1997;41:245-51.

32 Thomas LA, Veysey MJ, Murphy GM, et al. Influence of $\mathrm{pH}$ on the phase distribution of nascent deoxycholic acid in fresh human cecal aspirates. Am J Physiol 2001;281:G371-4.

33 Fadden K, Owen RW. Faecal steroids and colorectal cancer: the effect of lactulose on faecal bacterial metabolism in a continuous culture model of the large intestine. Eur J Cancer Prev 1992;1:13-127.

34 Plockinger U, Dienemann D, Quabbe HJ, et al. Gastrointestinal side-effects of octreotide during long-term treatment with acromegaly. J Clin Endocrinol Metab 1990:71:1658-62.

35 Catnach SM, Anderson JV, Fairclough PD. The effect of octreotide on gallstone prevalence and gallbladder motility in acromegaly. Gut 1993;34:270-3.

36 Montini $M$, Gianola D, Pagini MD, et al. Cholelithiasis and acromegaly: Therapeutic strategies. Clin Endocrinol 1994:40:401-8.

37 Bentley DW, Nichols RL, Condon RE, et al. The microflora of the human ileum and intra-abdominal colon: Results of direct needle aspiration at surgery and evaluation of the technique. J Lab Clin Med 1972;79:421-9.

38 Thomas LA, Veysey MJ, French G, et al. Bile acid metabolism by fresh human colonic contents: a comparison of caecal versus faecal samples. Gut $2001 ; 49: 835-42$

39 Veysey MJ, Mills TD, Reynolds CR, et al. "Colonomegaly" in acromegaly-a link with colorectal neoplasia? Gut 1997:42:A121.

40 Delhougne B, Deneux C, Abs R, et al. The prevalence of colonic polyps in acromegaly: a colonoscopic and pathological study in 103 patients. J Clin Endocrinol Metab 1995;80:3223-6.

41 Jenkins P, Fairclough PD, Richards T, et al. Acromegaly, colonic polyps and carcinoma. Clin Endocrinol 1997:47:17-22.

42 Stellini M, Veysey MJ, Thomas LA, et al. Role of bile acids in colonic neoplasia in human studies. In: Northfield TC, Ahmed H, Jazrawi R, et al, eds. Bile acids in hepatobiliary disease. Dordrecht: Kluwer Acad Publishers, 2000:268-74.

43 Sassolas G, Harris AG, James-Deidier A, and the French SMS 201-995 acromegaly study group. Long term effect of incremental doses of the somatostatin analog SMS 201-995 in 58 acromegalic patients. J Clin Endocrinol Metab 1990;71:391-7.

44 Schmidt K, Braulke C, Jacobi V, et al. Prevalence of gallstones in acromegalic patients with different treatment regimens. Eur I Clin Invest 1991;21:11A.

45 Singh S, Olliff J, O'Brien I, et al. Prevalence of gallstones in acromegalics untreated with somatostatin. Eur J Gastrolenterol Hepatol 1993;5:541-2.

46 Heaton KW, Braddon FE, Mountford RA, et al. Symptomatic and silent gallstones in the community. Gut 1991;32:316-20. 